Review

\title{
Brushed DC Motor Drives for Industrial and Automobile Applications with Emphasis on Control Techniques: A Comprehensive Review
}

\author{
Dimitris A. Barkas *, George C. Ioannidis, Constantinos S. Psomopoulos ${ }^{\circledR}$, Stavros D. Kaminaris \\ and Georgios A. Vokas \\ Department of Electrical \& Electronics Engineering, University of West Attica, 12244 Egaleo, Greece; \\ gioan@uniwa.gr (G.C.I.); cpsomop@uniwa.gr (C.S.P.); skamin@uniwa.gr (S.D.K.); gvokas@uniwa.gr (G.A.V.) \\ * Correspondence: d.barkas@uniwa.gr; Tel.: +30-210-538-1541
}

Received: 21 April 2020; Accepted: 25 May 2020; Published: 27 May 2020

\begin{abstract}
The current paper presents an inclusive survey about the $A C$ to $D C$ and $D C$ to $D C$ converters for brushed DC Motor Drives. An essential number of different AC to DC and DC to DC topologies and control techniques, applied on the brushed DC motor drives are presented. This extensive literature review exposes advantages, disadvantages and limitations besides giving the basic operating principles of various topologies and control techniques.
\end{abstract}

Keywords: dc motor drives; hard switching; soft switching; controlled-rectifiers; choppers; fuzzy logic controllers; artificial neural network controllers

\section{Introduction}

DC motors have been used for several decades. The DC network was the first developed electric network and was constructed to work on the DC electric network. Nowadays, the majority of industry installed motors consist of AC motors, due to their high-speed operation and their smaller volume and weight. Additionally, AC motors, due to their construction, require lighter maintenance and are cheaper compared to the DC motors. However, DC motors are still used for several reasons, including, wide speed range, starting and accelerating torques more than $400 \%$ of their rated values, good speed regulation and simpler and cheaper control systems. Their main applications, include manufacture of pulp, paper and paperboard, propulsion of electric vehicles, textile industries and public transportation, such as subway and trolley systems. Modern DC motor drives utilize power electronic devices and are subdivided to chopper-fed and controlled thyristor-fed drives.

DC motor drives can be categorized according to the way they manage the energy generated during braking of the DC motor [1-4]. From that point of view, there are non-regenerative and regenerative DC drives in industry. Non-regenerative DC drives are the most conventional type widely used. They have an ability to control motor speed and torque only in one direction, which means operation in the first-quadrant of the four quadrants of operations, as illustrated in Figure 1.

The controller output polarity can be reversed using a magnetic armature reversing contractor or using a manual switch. By operating the controller in this way, the motor armature direction is also reversed. The DC motor operates in the third quadrant of Figure 1. In both cases, torque and rotational direction are the same. Four-quadrant drives, or as usually referred regenerative DC drives, achieve to control both speed and direction of motor rotation. Moreover, regenerative DC drives can also control the direction of motor torque. These DC drives are named as "regenerative" due to the regeneration ability that they offer. The regeneration feature is the ability of the drive to convert the mechanical energy produced during the braking condition, into electrical energy, which is returned to 
the power source. During the drive operation in the first and third quadrants, the motor rotation and motor torque have got the same direction and the drive operates as a conventional drive without the regeneration capability.

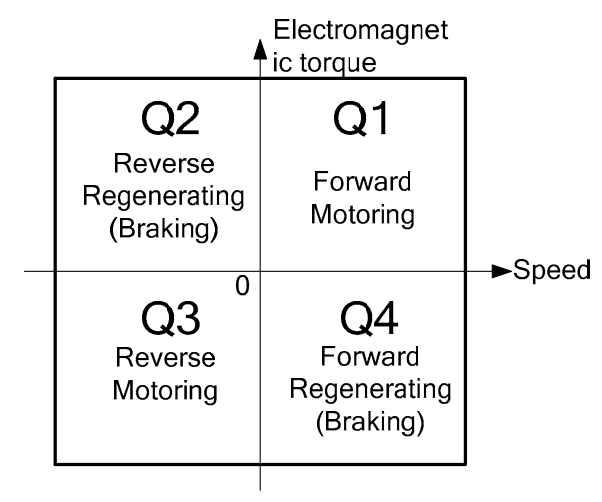

Figure 1. Quadrants of operation of a DC motor.

The special capabilities of regenerative drives exist only during the operation in the second and fourth quadrants. Operating in these quadrants, a braking force is provided due to the motor torque, which opposes to the direction of motor rotation. One characteristic of a high-performance regenerative drive is its ability to rapidly switch from braking to motoring modes and vice versa, controlling simultaneously the direction of motor rotation. A DC regenerative drive is practically a combination of two DC drives, which offer the operation of the motor in the first and fourth quadrants, or in the second and third quadrants, respectively.

The classification of DC motor drives can be done according to the type of the utilized converter, which controls the speed and the torque of the DC motor [2-4]. When a controlled one-phase or three-phase rectifier is used, then this drive category is called Controlled Rectifier-Fed or Thyristor-Fed DC motor drive. Another DC motor drive category is the Chopper-Fed, in which a DC to DC converter is used. The previous categories can be further subdivided into non-regenerative and regenerative DC motor drives according to the way they manage energy during braking condition.

There are a large number of converters that have been presented and analyzed in the literature. These converters operate using controlled rectifier circuits and they can be categorized according to the input power, as single-phase or three-phase, AC to DC converters [2-9]. The application of the above-mentioned converters varies according to the special requirements. These converters can operate at one, two or three quadrants. However, the fabrication of more efficient semiconductor switches, during last decades, has led to the development of new DC to DC converters. These DC to DC converters have the ability to operate at high frequencies, particularly in the range of tens of kHz. They also exhibit high response speed and their application for controlling DC motors is increased [2-5,10-26]. During the recent years, there has also been a trend in reducing the size, volume, and weight of the drive. Additionally, the requirement of controlling DC motors with low inductance, led to the development of converters which operate with even higher frequency and reduced ripple current. For these reasons, DC to DC converters were used [11-26]. At first these DC to DC converters were applied in switching power supplies [11-15] and they could not be applied for DC motor drives, especially for electric vehicle propulsion. They suffer from excessive voltage and current stresses $[13,15]$, and moreover they are unable to handle the backward power which is generated during the regenerative braking [16]. In the literature, another category of drives has been proposed which are suitable for DC motor drives, and this category is known as soft-switching DC to DC converters [17-26].

Additionally, the speed control of a DC motor is achieved using armature control methods, field control methods and combination of them. In armature control method the field current is kept approximately constant and the armature current is varied by a control signal provided by the 
controller, a PI controller for example. In this method, the field current is kept constant which means that flux density is constant resulting to a constant field flux in the field circuit. Therefore, the motor torque directly depends on armature current which can be easily varied by varying the armature voltage. In contrast, in combined armature and field control (obviously for separately excited DC motor), the speed can be varied from zero to rated value mainly by armature voltage control in the constant torque and linearly varying power region. The increase of the DC motor speed above its rated value can be achieved by reducing field flux in the so-called constant power and hyperbolic torque region. The combined armature and field speed control with torque and power are shown in Figure 2 [27].

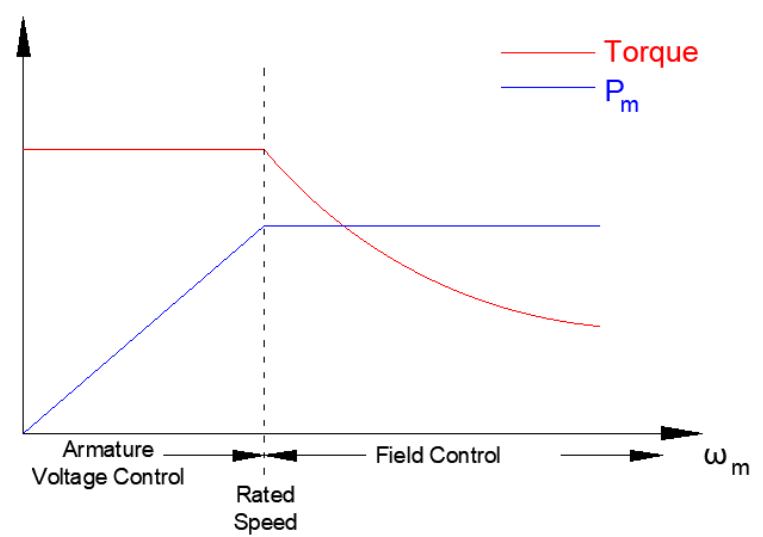

Figure 2. Combined armature and field control of DC motor [27].

Considering the field control methods, the most popular ones are the field voltage control with constant armature current and the field voltage control with constant armature voltage [28]. In the field voltage control with constant armature current, the use of a current generator is mandatory, and this is a basic disadvantage due to the high cost of such a generator, especially for high power applications. Additionally, as the rotor current maintains constant, a dangerous situation for the motor's life resulted, due to the high values of current in rotors that may occur. However, as the power input maintains constant and if the control device drives a low power device, then a low power reference signal is required to control the system instead of the use of a high precision with high gain amplifier. Additionally, using this control method, many motors could be connected in series when a high-power current generator is available, under specific system configuration [28]. In the field voltage control with constant armature voltage, the constant voltage generator is usually cheap, even in the case of high-power purposes. Additionally, when the power is supplied to the system using the constant voltage generator then the control signal is a low power signal. Moreover, as the usual cases are balanced armature voltage using a non-null back EMF (Electro-Magnetic Force), this configuration results to a limited number of peaks on the armature current [28].

The implementation of a complete DC motor drive involves the development of a controller which will drive the power circuit. There are many available techniques to implement such action, with the most popular categorization to be:

\section{$>$ Classical PID Controllers \\ $>$ Intelligent controllers.}

The work presented by the authors in this manuscript is an effort of extensive literature review, exposing advantages, disadvantages and limitations, besides giving the basic operating principles of various topologies and control techniques. Given the fact that this work is actually a review paper, there is no set method to ensure that all the literature available globally on the topic, was taken under consideration and the chances of the review being biased. The authors, firstly, present the topologies 
of DC motor drives, and secondly, they review the control techniques based on the most popular categorization already mentioned above.

\section{DC Motor Drives Topologies}

As it was mentioned before, DC motor drives are divided into Controlled Rectifier-Fed and Chopper-Fed DC Motor Drives.

\subsection{Controlled Rectifier-Fed DC Drives}

One of the main applications of the thyristor-based DC drive is the control of DC motors, which are equipped with brushes, in applications where the maintenance is higher but tolerable. The speed control is achieved based on the feed of a low-impedance adjustable DC voltage in the motor armature through the thyristor-based rectifier. Although the usual case is a three-phase system to feed the rectifier with power, when the motor power is up to a few kilowatts, a single-phase system can be used. On the other hand, in order to supply the field winding with energy, a single-phase system is used as the needed power is much lower comparing to the armature power (Figure 3).

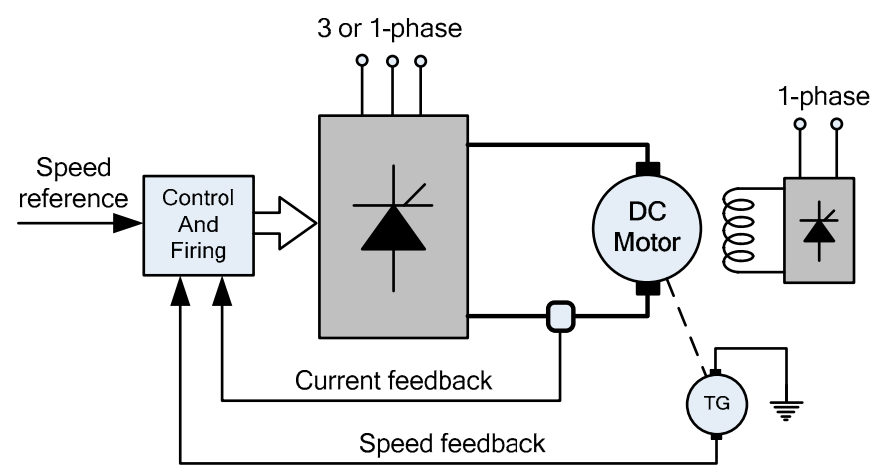

Figure 3. General closed-loop controlled rectifier-fed DC motor drive.

The main power circuit usually consists of one or four or six-thyristor circuit, which rectifies the incoming AC supply to produce a DC supply to the motor armature. Altering the firing angle of the thyristor/s the mean value of the rectified voltage can be varied and thus, the motor speed is controlled. The controlled rectifier produces a DC bus with an explicit ripple in the output voltage. This ripple component provokes pulsating current and fluxes in the motor, and in order to avoid excessive eddy-current losses and commutation problems, the motor poles and frame should be made of laminated material. It is a common practice that motors, supplied for use with thyristor drives, should have laminated construction. Nevertheless, older motors often have solid poles and/or frames so these motors will not always work satisfactorily with a rectifier-based power supply. It is also common that drive motors are supplied with an attached blower motor as standard. In this way, continuous ventilation is provided and the motor can operate continuously at full torque and lowest speeds without overheating [2-6].

Motor current and speed are the basic variables of interest which are monitored using low power control circuits. These variables are used in order to generate appropriate firing pulses so that the motor maintains constant speed despite load variation. The speed reference signal, as shown in Figure 3, is typically an analogue voltage varying from 0 to $10 \mathrm{~V}$ or from 0 to $5 \mathrm{~V}$ or -5 to $5 \mathrm{~V}$, and obtained from an appropriate speed-setting potentiometer or from elsewhere in the system. The power topology, the control and protective circuits constitute the converter. Standard modular converters are available as off-the-shelf items from $0.5 \mathrm{~kW}$ up to several hundred $\mathrm{kW}$, while larger drives will be tailored to specific requirements. Individual converters may be mounted in enclosures with isolators, fuses etc., or groups of converters may be mounted together to form a multi-motor drive. 
Figure 4 presents a separately excited DC motor. In this case, the supply is fed using a single-phase half wave converter [2-6]. This type of drives can drive the DC motor permitting its usage only in one quadrant, and it is used for small DC motors with rating power up to $0.5 \mathrm{~kW}$. The average output voltage for this converter can be found to be,

$$
\mathrm{V}_{\mathrm{o}}=\frac{\mathrm{V}_{\mathrm{m}}}{2 \pi}(1+\cos \alpha), \text { for } 0<\alpha<\pi
$$

where $V_{m}$ is the maximum value of the applied line voltage, and a is the firing angle.

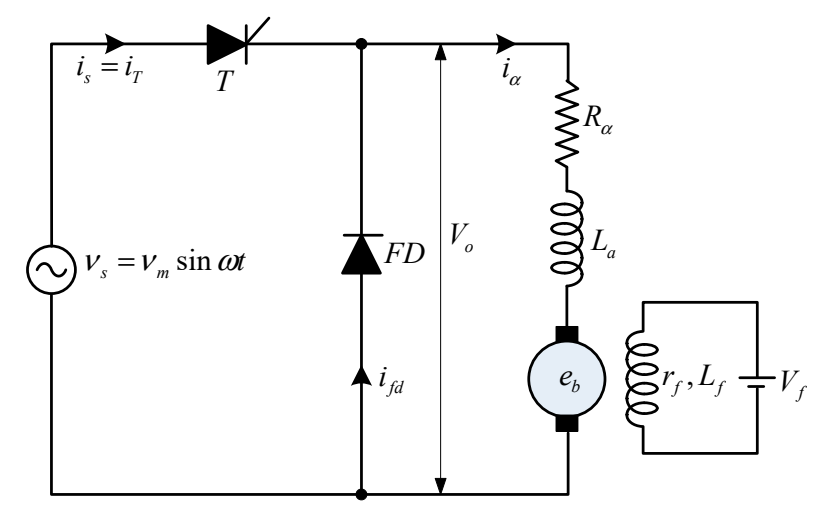

Figure 4. Single-phase half wave converter drive.

Figure 5 illustrates a separately excited motor which is supplied with electric power through a single-phase asymmetrical converter. As the diodes in the structure of Figure 5 cannot have at any instant a positive voltage across their terminals, it means that the motor's armature voltage cannot be negative. Consequently, this topology cannot be regenerative and it can operate only to the first quadrant of the torque-speed diagram. Additionally, its usage is limited for DC drives with total power up to $15 \mathrm{~kW}$. In order to protect the circuit from overvoltages, the used diodes should be an ultra-high-speed type, aiming to offer a trusted freewheeling path for the main power circuit. In the case of one-quadrant operation the fully controlled converters exhibit worst characteristics, in comparison to the half-controlled. Specifically, they have more harmonic distortion to the input current, more expensive control circuits, lower power factor and decreased mean value of the output voltage for the same firing angle. If this converter type is in continuous operation mode, then the average output voltage can be found to be [2-6]:

$$
\mathrm{V}_{\mathrm{o}}=\frac{\mathrm{V}_{\mathrm{m}}}{\pi}(1+\cos \alpha), \text { for } 0<\alpha<\pi .
$$

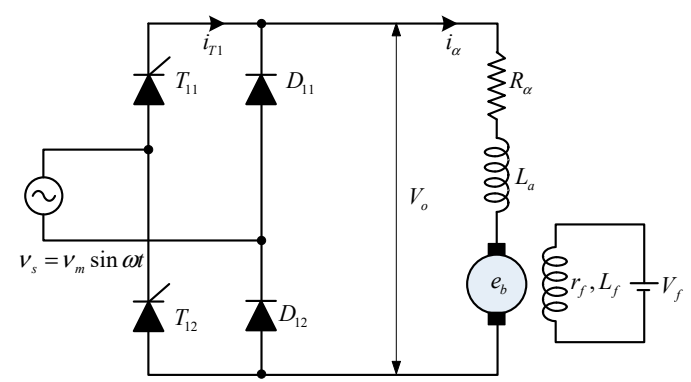

Figure 5. Single-phase half-controlled asymmetrical converter drive.

In Figure 6, a full wave converter is illustrated. In this converter type, the armature voltage upper limit is $+2 \mathrm{~V}_{\mathrm{m}} / \pi$ and the lower voltage limit is $-2 \mathrm{~V}_{\mathrm{m}} / \pi$. Consequently, this converter type operates in 
the first and fourth quadrants, and its usage is limited for motors up to $15 \mathrm{~kW}$. The output voltage for the full wave converter is described using the following equation [2-6]:

$$
\mathrm{V}_{\mathrm{o}}=\frac{2 \mathrm{~V}_{\mathrm{m}}}{\pi} \cos \alpha, \text { for } 0<\alpha<\pi
$$

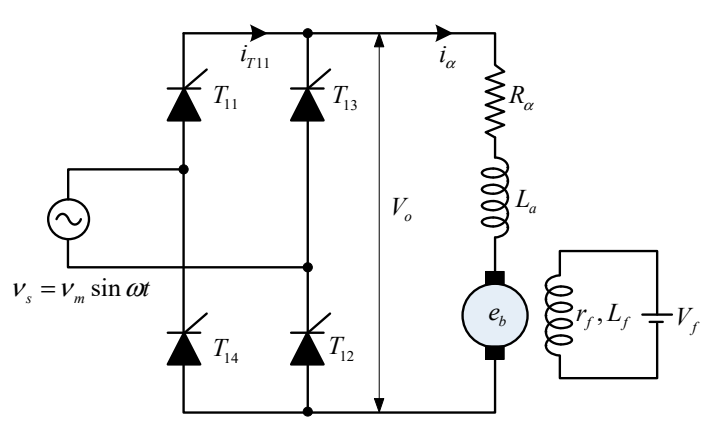

Figure 6. Single-phase fully-controlled converter drive.

Figure 7 depicts a single-phase fully-controlled dual converter drive. In this version, there is a back-to-back connection of two single-phase full wave converters. The first full wave converter supplies the armature with a positive voltage $+\mathrm{V}_{0}$, and has the ability to operate in the first and fourth quadrants. The second full wave converter feeds the armature with a negative voltage $-V_{o}$ and operates in the second and third quadrants. Obviously, this single-phase dual converter is a four-quadrant converter providing the four modes of operations, which are the motoring mode, the forward braking mode or forward regeneration mode, the reverse motoring mode and the reverse braking mode or reverse regeneration mode.

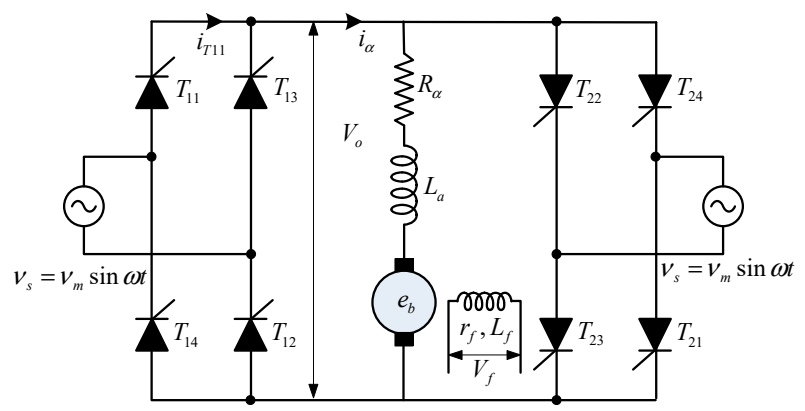

Figure 7. Single-phase fully-controlled dual converter drive.

The output voltage for the first, assuming that it operates at a firing angle $\alpha_{1}$, is [2-6]:

$$
\mathrm{V}_{\mathrm{o}}=\frac{\mathrm{V}_{\mathrm{m}}}{\pi}\left(1+\cos \alpha_{1}\right), \text { for } 0<\alpha<\pi
$$

In the same way, the output voltage for the second converter which operates at a firing angle $\alpha_{2}$ then is [2-6]:

$$
\mathrm{V}_{\mathrm{o}}=\frac{\mathrm{V}_{\mathrm{m}}}{\pi}\left(1+\cos \alpha_{2}\right) .
$$

The inverse operation, in this case, could be achieved through a field-reversal, which means that the motor's counter electromotive force (CEMF) will be reversed. However, this inversion is finally achieved with the inversion in the motor's armature current. The inversion through the armature's current presents the advantage of more rapid reversal. In addition, the DC motor drives provide the fastest dynamic response to changes in torque or speed commands. One desirable characteristic, which leads to a satisfactory operation of the control system is the armature current continuity. The continuity 
of armature current is a desirable feature for the satisfactory operation of the control system. Where an additional inductance is included in a series with the motor armature, the continuous-current operation can be achieved, without the certainty that a quite large inductor will lead to a continuous-current operation for all load conditions and speed.

The size of the necessary induction could be reduced by employing other converter configurations, such as three-phase AC to DC converters. However, these configurations do not ensure the complete elimination of the inductor's size.

A three-phase fully-controlled converter is illustrated in Figure 8 [2-6]. This type of converter works in two quadrants of operation and traditionally is used for large motor applications with a load up to $140 \mathrm{~kW}$. A variation of this converter type can be achieved, which replaces the three thyristors by diodes. This configuration is limited to the first quadrant of operation and introduces even harmonics into the line currents making prohibitive its application on large power applications. The output voltage of the three-phase fully controlled converter in continuous-mode operation is given by the following equation [2-6],

$$
\mathrm{V}_{\mathrm{o}}=\frac{3 \mathrm{~V}_{\mathrm{m}, \mathrm{L}}}{\pi} \cos \alpha, \text { for } 0<\alpha<\pi
$$

where $V_{m, L}$ is the maximum value of the line voltage.

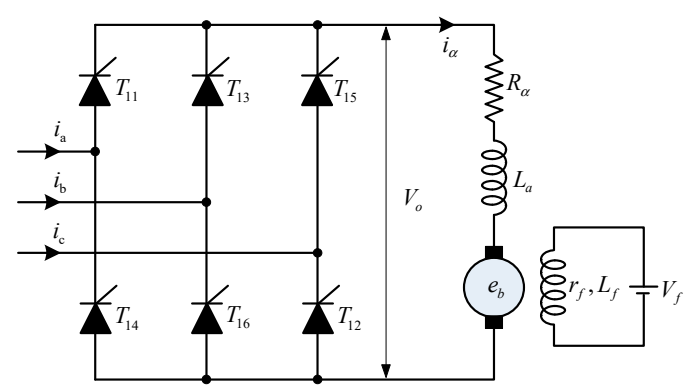

Figure 8. Three-phase fully-controlled converter.

When four-quadrant operation is needed, then a dual three-phase fully-controlled topology, as Figure 9 illustrates, could be used.

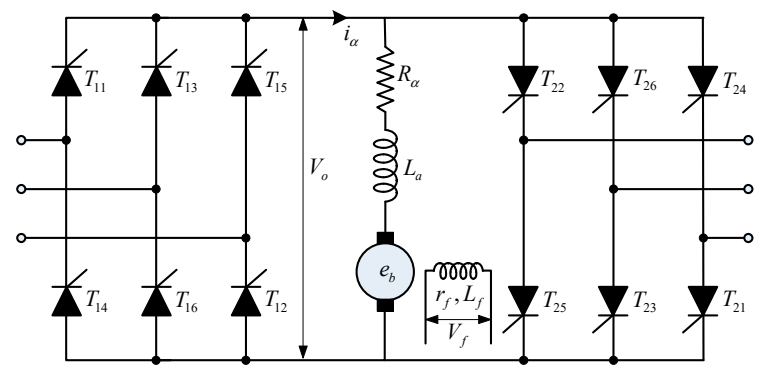

Figure 9. Dual Three-phase fully-controlled converter.

Finally, the summary of the key characteristics of controlled rectifier-fed drives are presented in Table 1. 
Table 1. Main characteristics of controlled rectifier-fed drives.

\begin{tabular}{|c|c|c|c|c|}
\hline \multicolumn{5}{|c|}{ General Features } \\
\hline $\begin{array}{l}\text { Explicit ripple in } \\
\text { the output voltage }\end{array}$ & - $\quad 50 / 60 \mathrm{~Hz}$ & ration & $\begin{array}{ll}\text { - } & \text { Low } \\
\text { order harmonics }\end{array}$ & $\begin{array}{ll}- & 0.5 \mathrm{~kW} \text { to } \\
& \text { hundred } \mathrm{kW}\end{array}$ \\
\hline \multicolumn{2}{|c|}{$\begin{array}{l}\text { Single-phase half wave } \\
\text { - } \quad 1 Q \text { operation } \\
\text { - } \quad \text { For small DC motors up to } 0.5 \mathrm{~kW} \\
\text { Single-phase asymmetrical converter } \\
\text { - } \quad 1 Q \text { operation } \\
\text { - } \quad \text { For DC motors up to } 15 \mathrm{~kW}\end{array}$} & \multicolumn{3}{|c|}{$\begin{array}{l}\text { Single-Phase fully controlled converter } \\
\text { - } \quad 2 \text { Q operation } \\
\text { - } \quad \text { For motors up to } 15 \mathrm{~kW} \\
\text { - } \quad \text { Compared to half-controlled: } \\
\text { - } \quad \text { More input current harmonic distortion } \\
\text { - } \quad \text { More expensive control circuits } \\
\text { - } \quad \text { Lower power factor } \\
\text { - } \quad \text { Decreased output voltage mean value for the same } \\
\text { Single-Phase Fully-Controlled Dual converter } \\
\text { - } \quad \text { 4Q operation } \\
\text { - } \quad \text { Rapid reversal } \\
\text { - Fastest dynamic response to changes in torque or } \\
\quad \text { speed commands }\end{array}$} \\
\hline \multicolumn{2}{|c|}{$\begin{array}{l}\text { Three-phase half-controlled converter } \\
\text { - } 1 \text { Q operation } \\
\text { - Introduces more harmonics into the } \\
\text { line currents } \\
\text { - Its usage is prohibitive on large } \\
\text { power applications }\end{array}$} & \multicolumn{3}{|c|}{$\begin{array}{l}\text { Three phase fully-controlled converter } \\
\text { - } \quad \text { QQ operation } \\
\text { - } \quad \text { Motors up to } 140 \mathrm{~kW} \\
\text { Three-phase Dual fully-controlled converter } \\
\text { - } \quad 4 Q \text { operation } \\
\text { - } \quad \text { Rapid reversal } \\
\text { - } \quad \text { Fastest dynamic response to changes in torque or } \\
\quad \text { speed commands }\end{array}$} \\
\hline
\end{tabular}

\subsection{Chopper-Fed DC Motor Drives}

A chopper device is to be used when the aim is to convert a fixed DC voltage into a variable DC output voltage. Chopper topology behaves in an identical manner as a transformer in the AC current. Choppers are frequently used all over the world for rapid transit systems, and in some other applications, such as mine haulers, trolley cars, forklift trucks and marine hoist. Their most significant advantages are the regeneration operation capability, their fast response and their high efficiency. The applied semiconductor devices in the chopper drives are the power BJT (Bipolar Junction Transistor), the forced commutated thyristor, MOSFET (Metal-Oxid-Semiconductor Field-Effect-Transistor), IGBT (Insulated-Gate Bipolar Transistor), MCT (MOS-Controlled Thryristor) and GTO (Gate Turn-Off Thyristor). Independent of the applied combination, the device actually operates like a switch, which means that when the switch is under the "on" operation, then the current flows through the load. The on-state voltage drop on the power semiconductors is in the range of $0.5 \mathrm{~V}$ to $2.5 \mathrm{~V}$ across them, and the power losses can be determined if their switching characteristics are also taken into consideration [2-6].

The converters can be categorized into two groups, according to the way that they transit from one switching state to another. These converter categories are the hard-switching and the soft-switching converters.

\subsubsection{Hard-Switching Converters for DC Drives}

Conventional Pulse Width Modulated (PWM) converters have been used in switched mode over the last few decades. However, in the case of power switches, they must cut off the load current during the turn-on and turn-off time intervals when they operate in hard-switching mode. The term hard-switching arises due to the stressful switching situation of the power electronic devices. The switching behavior for a hard-switching device is illustrated in Figure 10. The power device operates 
under high voltage and current simultaneously during the turn-or or turn-off process, a situation which leads into high switching stress and losses.

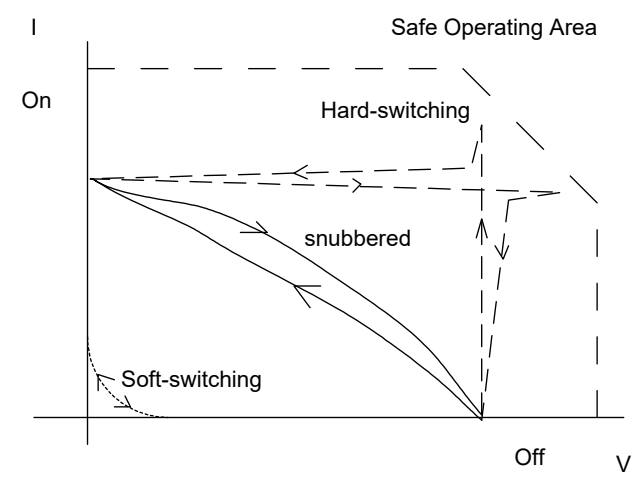

Figure 10. Hard and soft switching characteristics.

The reduction of stress and losses under hard-switching conditions is a phenomenon that needs to be eliminated. For this reason, the addition of dissipative passive snubbers, into the power circuits, is a frequent solution, diverting by this way the stress and losses to these passive snubber circuits. Through this addition, a reduction of the $\mathrm{dv} / \mathrm{dt}$ and $\mathrm{di} / \mathrm{dt}$ can be achieved. The reduction on the maximum switching frequency of the converters is also another factor aimed at reducing the switching losses, as they are proportional to the switching frequency. The typical switching frequency for the power converters is limited and typically lies between $20 \mathrm{kHz}$ and $50 \mathrm{kHz}$. Additionally, there are considerable transient effects in the converters, due to the existence of stray capacitances and inductances in the power circuits, which lead to the rise in electromagnetic interference (EMI) problems [5].

Figure 11 presents a single-switch chopper. The switching device can be selected as a BJT, thyristor, MOSFET or IGBT. Its operation is limited to the first quadrant, which means motoring operation, as it can only supply positive voltage and current into the DC motor's armature. In the case of continuous conduction operation, the equations which govern its operation are [5],

$$
\begin{gathered}
V_{\mathrm{o}}=\mathrm{D} \cdot \mathrm{V}_{\text {in }} \\
\mathrm{V}_{\mathrm{r}}=\mathrm{V}_{\text {in }} \sqrt{\mathrm{D}(1-\mathrm{D})}, \\
\overline{\mathrm{I}}_{\mathrm{sw}}=\mathrm{D} \frac{\mathrm{V}_{\text {in }}-\mathrm{e}_{\mathrm{b}}-\frac{\tau}{\mathrm{T}} \mathrm{I}_{\mathrm{p}-\mathrm{p},}}{\mathrm{R}_{\mathrm{a}}} \\
\overline{\mathrm{I}}_{\mathrm{D}}=\frac{\tau}{\mathrm{T}} \mathrm{I}_{\mathrm{p}-\mathrm{p}}-\mathrm{e}_{\mathrm{b}} \frac{1-\mathrm{D}}{\mathrm{R}_{\mathrm{a}}}, \\
\mathrm{I}_{\mathrm{p}-\mathrm{p}}=\frac{\frac{\mathrm{V}_{\text {in }}}{\mathrm{R}_{\mathrm{a}}}\left(1-\mathrm{e}^{-\mathrm{D} \cdot \mathrm{T} / \tau}\right)\left(1-\mathrm{e}^{-(1-\mathrm{D}) \cdot \mathrm{T} / \tau}\right)}{1-\mathrm{e}^{-T / \tau}} \\
\tau=\frac{\mathrm{L}_{\mathrm{a}}}{\mathrm{R}_{\mathrm{a}}},
\end{gathered}
$$

where $\mathrm{V}_{\mathrm{o}}, \mathrm{e}_{\mathrm{b}}, \mathrm{V}_{\mathrm{r}}, \overline{\mathrm{I}}_{\mathrm{sw}}, \overline{\mathrm{I}}_{\mathrm{D}}, \mathrm{I}_{\mathrm{p}-\mathrm{p}}, \mathrm{T}, \mathrm{D}$ are the average output voltage, back EMF voltage, output $\mathrm{AC}$ ripple voltage, average switch current, average diode current, peak to peak output ripple current, switching period, and duty cycle, respectively.

Figure 12a presents a two-quadrant hard-switching DC motor drive [5]. The first-quadrant chopper is formed by the SW1 and D1 components through which the energy is fed by the $\mathrm{V}_{\text {in }}$ source to the DC motor, resulting into the motoring mode of operation. Correspondingly, a fourth-quadrant operation is formed by the SW2 and D2 components by which the energy is fed by the $\mathrm{V}_{\text {in }}$ source to the DC motor, resulting into the regeneration mode of operation. Equations (7)-(12) are still valid, when 
the circuit operates in continuous conduction mode. The average diodes and switches currents are dependent on the polarity of the maximum and minimum peak output current, and on the polarity of the mean value of the output current. For these reasons, the estimation of these average current values is more complex. When the converter operates in the first quadrant, the average currents flowing through the SW1 and D1 components can be calculated using Equations (9) and (1), respectively, while the corresponding currents flowing through the SW2 and D2 components are zero [5].

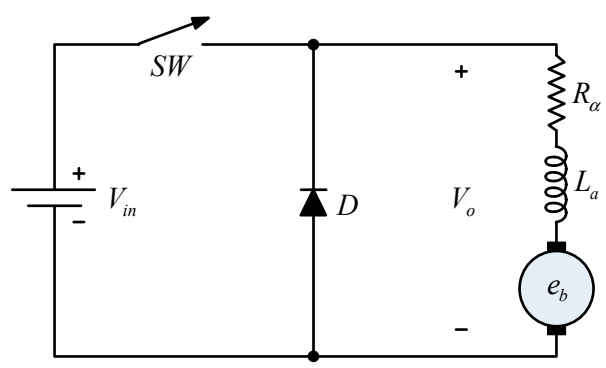

Figure 11. One-quadrant hard switching DC motor drive.

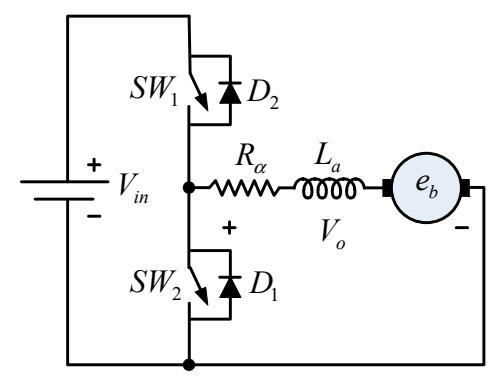

a)

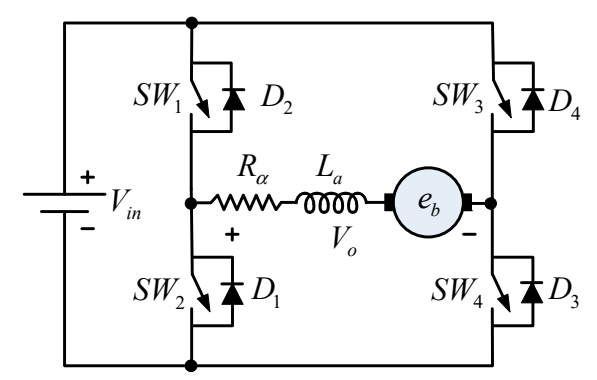

b)

Figure 12. (a) Two-quadrant and (b) Four-quadrant hard-switching DC motor drives.

Figure $12 \mathrm{~b}$ depicts an H-bridge or four-quadrant DC chopper [5]. The existence of four switches leads into different control methods in order to produce four-quadrant output voltage and current by the meaning of bidirectional current and voltage. Aiming at reducing the distortion, in all methods complementary switching components are used in each leg (T1 or T4 can be in "on" state but not both and correspondingly T2 and T3 but not both). The described operation philosophy ensures the current continuity around the zero-current output [5].

This H-bridge can be controlled in the same way such as, when two independent two-quadrant choppers to be controlled. The main restriction is that the switches in the same leg must not be conducted simultaneously. The first chopper is formed by the conduction of T1 and T4 switches with D1 and D4 diodes. The first chopper works at first and second quadrants, where output current is positive while output voltage is bidirectional, i.e. \pm Vo. A second chopper is formed by the conduction of T2 and T3 switches with D2 and D3 diodes, which means an operation at third and fourth quadrants. In this case, a negative output current is available, with bidirectional output voltage $\pm V_{\mathrm{o}}$. The two above-mentioned two-quadrant choppers, embedded in the same topology, ensure the DC motor's operation into the four quadrants. Another control method, for the H-bridge converter, is to unify the operation of all four switches [5].

Depending on whether the zero output voltage loops are employed or not, using the above control methods, the converter's output voltage can be either bipolar or multilevel. In the case of a bipolar output, there is an increment to the ripple current value. However, a faster current reversal is facilitated, with minimum crossover distortion. The direction of the output current does not influence the operation. According to the above, two H-bridge control techniques can be considered which are known as the three-level output voltage and the bipolar output voltage. 
In the case of a bipolar output voltage, the average output voltage and the AC ripple voltage can be described by the following equations [5]:

$$
\begin{gathered}
V_{\mathrm{o}}=(2 \mathrm{D}-1) \mathrm{V}_{\mathrm{in}}, \\
\mathrm{V}_{\mathrm{r}}=2 \mathrm{~V}_{\text {in }} \sqrt{\mathrm{D}(1-\mathrm{D})},
\end{gathered}
$$

The peak to peak output ripple current is twice the value given by (11). For three-level output and for $\mathrm{D} \leq 0.5$ :

$$
\begin{gathered}
V_{\mathrm{o}}=(2 \mathrm{D}-1) \mathrm{V}_{\mathrm{in},} \\
\mathrm{V}_{\mathrm{r}}=\sqrt{2} \mathrm{~V}_{\mathrm{in}} \sqrt{\mathrm{D}(1-2 \mathrm{D}),}
\end{gathered}
$$

and for $\mathrm{D} \geq 0.5$

$$
\begin{gathered}
\mathrm{V}_{\mathrm{o}}=(2 \mathrm{D}-1) \mathrm{V}_{\mathrm{in}} \\
\mathrm{V}_{\mathrm{r}}=\sqrt{2} \mathrm{~V}_{\mathrm{in}} \sqrt{(2 \mathrm{D}-1)(1-\mathrm{D})}
\end{gathered}
$$

\subsubsection{Soft-Switching Converters for DC Drives}

During the hard-switching operation of DC to DC converters, the electronic switches operate under the full load when the switches turn on or turn off. This kind of operation stresses the semi-conductors leading into increased losses. These losses are linearly increased with the converters' switching frequency. Additionally, the large $\mathrm{dv} / \mathrm{dt}$ and di/dt result in increased EMI problems. The above abnormal conditions are originated from the need of smaller converters' size and weight, thus increased power density.

A strategy to minimize the above-mentioned shortcomings is to change converter's switch state when the current flowing through it or the voltage across it, is zero at switching instant. This can be succeeded with the usage of LC resonant circuits, aiming to shape the voltage or current waveforms forcing the power device to switch at zero-voltage (ZV) or zero-current (ZC) condition. The usage of LC resonant circuits leads to the well-known "resonant soft-switching" converters. In the literature [16-26], soft-switching DC-DC topologies have been proposed for DC motor drives, offering the ability for motoring and regenerative braking, an operation which can be achieved by the bidirectional power flow. The operation of soft-switching topologies is based on resonant elements, while their characteristic impedance and their angular frequency $\omega$ can be described as:

$$
\mathrm{Z}=\sqrt{\mathrm{L}_{\mathrm{r}} / \mathrm{C}_{\mathrm{r}}}, \omega=\sqrt{1 / \mathrm{L}_{\mathrm{r}} \mathrm{C}_{\mathrm{r}}}
$$

Figure 13 illustrates a two-quadrant (2Q) Zero-Voltage Multi-Resonant (ZVMR) converter [18]. This topology is composed by a conventional 2Q-PWM DC drive, two resonant capacitors and a resonant inductor. It is applied in systems where motoring and regenerative braking modes of DC motors are to be achieved, offering by this way bidirectional flow in electric power. One advantage for this soft-switching converter is the operation with high switching frequencies, typical above $100 \mathrm{kHz}$, with the ripple current value of DC motor maintained in low magnitudes, while the switching losses are quite low due to Zero-Voltage-Switching (ZVS) for all switches. Additionally, this converter provides load variation and full ranges of voltage conversion.

This ZVMR converter uses all the built-in diodes and has the ability to absorb all major parasitic. Additionally, it is important to be noted that the usage of ZVR technology is highly desirable for converters using MOSFETs. This is because MOSFETs suffer from extremely high magnitudes in capacitive voltage turn-on losses. As the 2Q-ZVMR behaves as a constant source after reaching the maximum output current value, it handles short-circuit down to no-load conditions without any additional measures. 


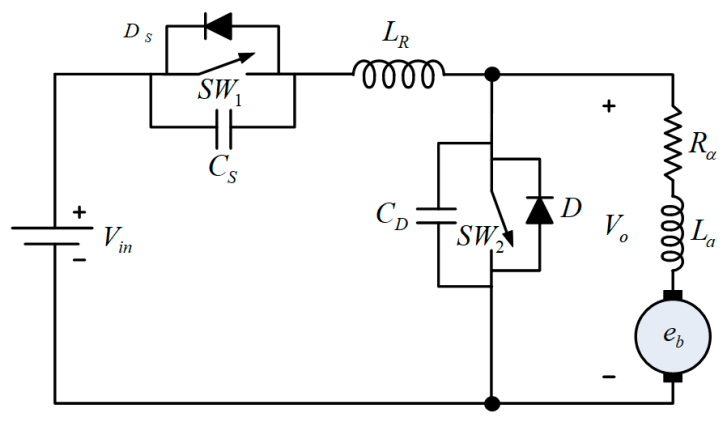

Figure 13. Zero-voltage multi-resonant converter fed DC motor drive.

The power rating of the semiconductors (MOSFET) associated with the MR cell is higher as compared with the conventional two-quadrant PWM DC drive, due to the circulating energy and the conduction losses.

Figure 14 illustrates a 2Q Zero-Voltage-Transition (ZVT) converter [19], and it has the ability to operate in both motoring and regenerative braking modes of DC motor drives, by this way offering bidirectional flow in electric power. In contrast to the conventional 2Q-PWM DC drives, the 2Q-ZVT converter needs some extra components such as, a resonant capacitor, two auxiliary switches and a resonant inductor.

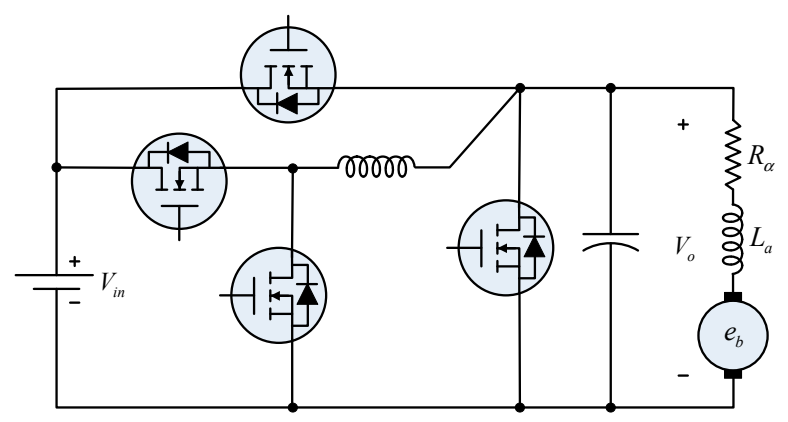

Figure 14. Zero-voltage-transition converter fed DC motor drive.

The 2Q-ZVT converter presents some basic advantages such as unity device current and voltage stress during the motoring and regenerative modes of operation, zero voltage switching for all the diodes and main switches, same resonant tank for both, backward and forward power flows, full utilization for all the built-in diodes of the power switches and simple circuit topology. The above advantages make the 2Q-ZVT converters to operate with high switching frequency, high efficiency and high-power density.

Additionally, an appropriate control system which will control the semiconductor switches is of major importance for this converter type. This control system can be achieved using a Digital Signal Processor (DSP).

Figure 15 depicts a 2Q Zero-Current-Transition (ZCT) converter [21]. As for the two previous topologies, this converter can operate in motoring and regenerative braking operation modes. In comparison to its PWM counterpart, this topology requires a resonant capacitor, a resonant inductor and two auxiliary switches.

This converter type exhibits some important advantage such as the zero-current switching for all the diodes and switches, main and auxiliary, same resonant tan for both backward and forward power flows, full utilization of all built-in diodes of the power switches, minimum current and voltage stresses, low cost and simple circuit topology. These characteristics lead to the deployment of medium frequency switching characteristics, in the range of $50 \mathrm{kHz}$, high efficiency and high-power density. 


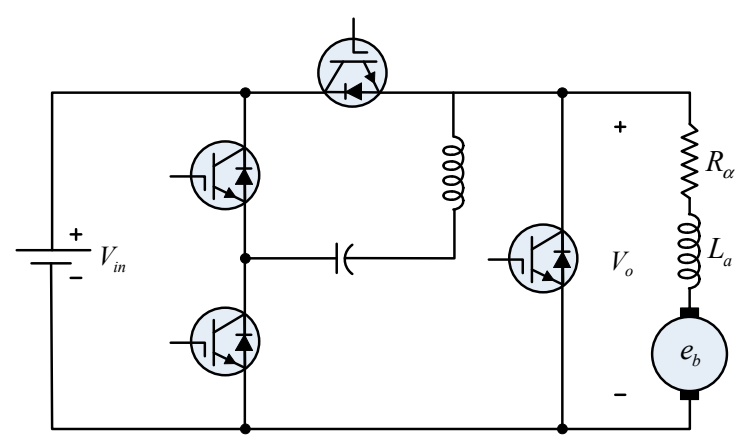

Figure 15. Zero-current-transition converter fed DC motor drive.

The 2Q-ZCT converter is usually applied for medium-power DC motor applications, in the range of few kW, using as main switching power devices the IGBTs (Insulated-Gate Bipolar Transistors). IGBTs usually suffer from severe inductive turn-off and diode reverse recovery turn-on losses.

Figure 16 presents a four-quadrant Zero-Voltage-Transition (4Q-ZVT) converter [21,22]. MOSFET power semiconductors are mainly used in this type of converter. It also gives the chance of operation in motoring and regenerative braking in both forward and reversible operation of DC motor drives. The 4Q-ZVT exhibits some basic advantages such as simple circuit topology, unity current and voltage stress and zero voltage switching for all main and auxiliary diodes and switches. Additionally, full utilization of all built-in diodes of the power switches can be achieved minimizing by this way the overall hardware cost, and it uses the same resonant tank for both backward and forward power flows. The above-mentioned characteristics lead to high efficiency and power density of the converter. The zero-voltage switching operation can be realized with the utilization of two sets of resonant tanks. The first set includes, the resonant capacitors $C_{a} / 2$, the inductor $L_{a}$ and the auxiliary switches $S_{a}$ and $S_{a}{ }^{\prime}$ for soft switching $S_{1}$ and $S_{4}$. The second set includes, the resonant capacitors $C_{b} / 2$, the inductor $L_{b}$ and the auxiliary switches $S_{b}$ and $S_{b}{ }^{\prime}$ for soft switching $S_{2}$ and $S_{3}$. As it can clearly be seen in Figure 16, there are two 2Q-ZVT converters which simultaneously fed the DC motor.

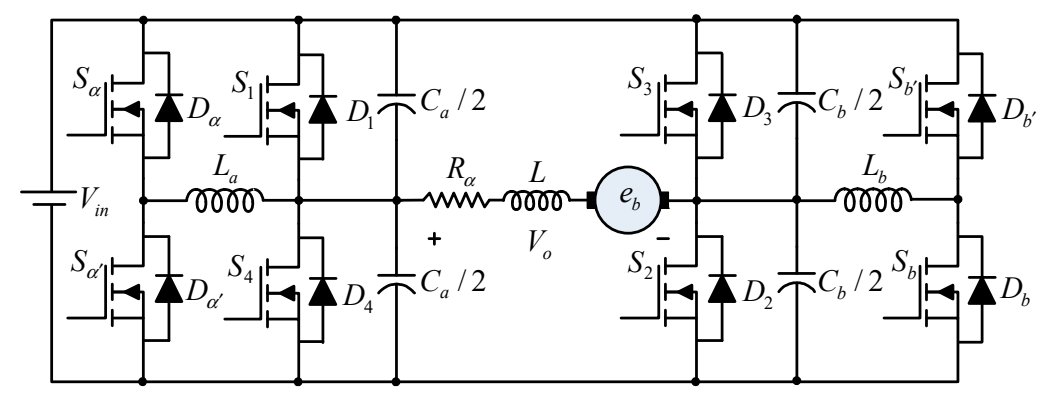

Figure 16. 4Q-ZVT converter fed DC motor drive.

Figure 17 presents a 4Q-ZCT (four-quadrant Zero-Current-Transition) converter [22]. The structuring power elements for this converter are the IGBTs, and it can be used for motoring and regenerative braking for DC motors, offering the possibility for forward and reversible operations as well.

The achievement of ZCS operation requires two sets of resonant tanks. The first tank includes a resonant capacitor $C_{a}$, an inductor $L_{a}$ and the auxiliary switches $S_{a}$ and $S_{a}{ }^{\prime}$, for soft switching of $S_{1}$ and $S_{4}$. The second one includes a resonant capacitor $C_{b}$, an inductor $L_{b}$ and the auxiliary switches $S_{b}$ and $S_{b}{ }^{\prime}$ in order to achieve soft switching of $S_{2}$ and $S_{3}$. As it can clearly be seen in Figure 17, there are two 2Q-ZCT converters which simultaneously fed the DC motor. The 4Q-ZCT presents the same characteristics as its 2Q-ZCT ancestor. The 4Q-ZCT topology is applicable for DC motors with power up to $5 \mathrm{~kW}$, while its semiconductors can operate in high frequencies. 


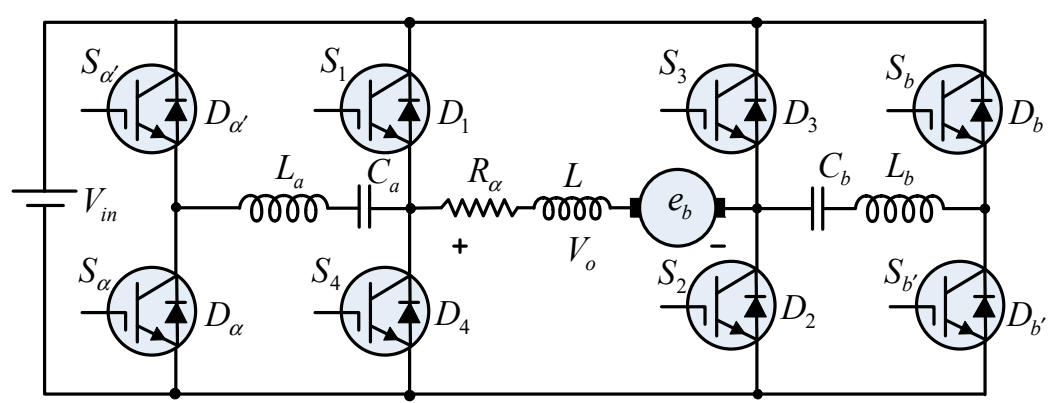

Figure 17. 4Q-ZCT converter fed DC motor drive.

\subsection{Comparative Evaluation of DC Motor Drives}

In industrial applications, such as printing, mining, cranes and metals shaping applications, controlled rectifier-fed DC drives are common choice. If the converter is indented to supply motors up to a few kilowatts then both the three-phase and single-phase mains could be used. However, when the application includes larger motors, with power above the $15 \mathrm{~kW}$ then traditional three-phase is used as main supply. The standard compact converters are available in sizes from $0.5 \mathrm{~kW}$ up to several hundred $\mathrm{kW}$. The controlled rectifier circuits with are available are differentiated according to the application. The single-phase controlled rectifiers can be categorized into one-quadrant, two-quadrant, and four-quadrant topologies.

In the case of one-quadrant converters, both half wave topologies and asymmetrical semi-converters have been manufactured. The half wave $1 \mathrm{Q}$ topologies are used to control DC motors with power up to $0.5 \mathrm{~kW}$, while the asymmetrical one is used for power up to $15 \mathrm{~kW}$. The half-controlled converters present important characteristics, in comparison to the fully controlled, such as cheaper control circuits, better power factor, increased mean value of the output voltage for the same firing angle, and smaller total harmonic distortion on the current in the input side. Moreover, in the case of $2 \mathrm{Q}$ topologies, the full wave converters are more appropriate for applications up to $15 \mathrm{~kW}$, while if a $4 \mathrm{Q}$ operation is of major need then the single-phase dual converter is the ideal choice for power up to $15 \mathrm{~kW}$.

Three-phase controlled rectifiers can also be categorized in $1 \mathrm{Q}, 2 \mathrm{Q}$ and $4 \mathrm{Q}$ topologies. The most famous and traditionally used AC to DC converter is the fully controlled, especially for applications with rated power up to $140 \mathrm{~kW}$, although there are half-controlled three-phase converters. In the case of half-controlled topology (three diodes replace the three thyristors) total harmonic distortion on the line current waveform is increased the and consequently it is assumed to be unsuitable especially for large applications. Furthermore, the half-controlled converters provide $1 \mathrm{Q}$ operation in contrast to the fully-controlled which provide $2 \mathrm{Q}$ operation. Finally, when the $4 \mathrm{Q}$ operation is required, then the dual three-phase fully-controlled converters should be used.

On the other hand, choppers are used worldwide especially for rapid transit systems. Because of their high efficiency, fast response and the regeneration capability, they have replaced the conventional controlled-rectifier converter in many DC applications. Additionally, they present decreased motor losses and torque ripple, because of the decreased armature ripple current, a phenomenon resulting from the high switching frequency.

Choppers can also be divided in two major categories: Hard-switching and soft-switching. These converters can both operate in one, two or four quadrants. Depending on the required frequency and the DC motor power, hard-switching choppers utilize GTOs, BJTs, MCTs, MOSFETs, thyristors and IGBTs as semiconductor switches. In case that low switching frequencies, up to several hundred $\mathrm{Hz}$, and high-power requirements are needed, thyristors and GTOs are utilized. When the application requires high switching frequencies, in the range of $20-50 \mathrm{kHz}$, and the motors' power is limited to low or medium values, then IGBTs and MOSFETs are mainly used, and in some cases BJTs as well. The employment of PWM control techniques is usually needed for all the above chopper cases. 
Table 2. Cont.

\begin{tabular}{|c|c|c|c|}
\hline \multicolumn{4}{|c|}{ Soft-Switching Converters } \\
\hline $\begin{array}{l}\text { 2Q-ZVMR Converter } \\
\text { - } \quad \text { 2Q Operation } \\
\text { - } \quad \text { Quite low switching losses } \\
\text { - } \quad \text { Provides load variation and full ranges o } \\
\text { 2Q ZVT Converter } \\
\text { - } \quad \text { 2Q Operation } \\
\text { - } \quad \text { Unity device current and voltage stress } \\
\text { - } \quad \text { Zero voltage switching } \\
\text { 2Q ZCT Converter } \\
\text { - } \quad \text { 2Q Operation } \\
-\quad \text { Zero current switching } \\
-\quad \text { Minimum current and voltage stresses } \\
-\quad \text { Switching frequency in the range of } 50 \mathrm{k} \\
-\quad \text { For medium-power DC motor applicatio }\end{array}$ & of voltage conversion & $\begin{array}{lr}4 \mathrm{Q} Z \mathrm{ZVT} \\
\text { - } & 4 \mathrm{Q} \\
\text { - } & \mathrm{Uni} \\
\text { - } & \mathrm{Zer} \\
\text { - } & \mathrm{Hig} \\
4 \mathrm{Q} Z \mathrm{ZCT} \\
\text { - } & 4 \mathrm{Q} \\
\text { - } & \mathrm{San} \\
\text { - } & \mathrm{Por}\end{array}$ & $\begin{array}{l}\text { verter } \\
\text { ration } \\
\text { urrent and voltage stress } \\
\text { ltage switching } \\
\text { pwer density } \\
\text { verter } \\
\text { ration } \\
\text { haracteristics as 2Q-ZCT } \\
\text { up to } 5 \mathrm{~kW}\end{array}$ \\
\hline
\end{tabular}

\section{Control Techniques for DC Motor Drives}

During the last decades, a lot of different control techniques have been introduced in order to control the speed and the torque of direct current motors. The control techniques are very important in order to ensure proper function and performance of an electric drive system. In the bibliography there are a lot of different control techniques and each technique can be applied with some different modes. This review paper illustrates some basic control techniques based on conventional PID controllers and intelligent controllers as well.

\subsection{Classic PID Controllers}

Over the last years, traditional controllers for DC motor were based on the Proportional Integrative and Differential (PID) controller. Some other subcategories of DC motor controllers can occur, beginning from the PID controller [23]:

$>$ Proportional $(\mathrm{P})$ based control technique

$>$ Proportional-Integral (PI) based control technique

$>$ Proportional-Differential (PD) based control technique

$>$ Proportional-Integral-Differential (PID) based control technique

The idea of a PID controller and its subcategories is to take as a feedback a special characteristic of the driving system and a setting point for this special characteristic, and applying some mathematical processes to achieve this setting point to the system's output. Such a special characteristic can be the speed or/and the torque of the DC motor. The basic block diagram of a PID controller is illustrated in Figure 18 where the PID controller has got as input the difference between feedback signal $y(t)$ and reference signal $r(t)$ and this difference feeds the PID controller block [24].

As Figure 18 illustrates, the full PID controller consists of three control parts, the proportional part, the integral part and the differential part. Each part calculates a specific mathematical operation. These mathematical operations are shown in Figure 18 as well. The output of the full PID controller, according to the Figure 18, is:

$$
u(t)=k_{p} \cdot e(t)+k_{i} \int_{0}^{t} e(\tau) d \tau+k_{d} \frac{d e(t)}{d t} .
$$


Whereas, the transfer function of the PID, calculated by the Laplace transform of (20) is,

$$
\mathrm{G}(\mathrm{s})=\frac{\mathrm{u}(\mathrm{t})}{\mathrm{e}(\mathrm{t})}=\mathrm{k}_{\mathrm{p}}+\frac{\mathrm{k}_{\mathrm{i}}}{\mathrm{s}}+\mathrm{k}_{\mathrm{d}} \cdot \mathrm{s}
$$

where $k_{p}, k_{i}, k_{d}$ are the gain factors for proportional, integral, and derivative, operations respectively.

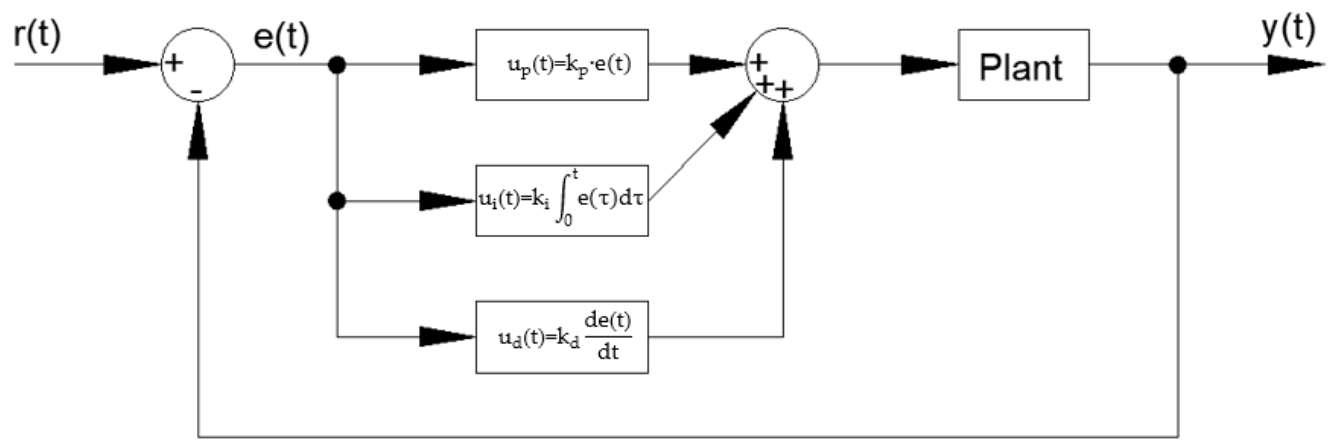

Figure 18. PID Controller internal block structure [24].

Depending on the values of these factors, the above mentioned different conventional controllers can be implemented. For example, if $\mathrm{k}_{\mathrm{p}} \neq 0, \mathrm{k}_{\mathrm{i}} \neq \mathrm{k}_{\mathrm{d}} \neq 0$ then a PID controller is implemented. If $\mathrm{k}_{\mathrm{p}} \neq 0, \mathrm{k}_{\mathrm{i}} \neq, \mathrm{k}_{\mathrm{d}}=0$ then a PI controller is implemented and so on.

In a PI the ' $\mathrm{P}$ ' component determines the reaction to current error, whereas ' $\mathrm{I}$ ' determines the reaction to the sum of recently appeared errors. According to the PI tuning procedure, the typical objectives are [25]:

$>$ Closed-loop stability. The closed-loop system output remains bounded for bounded input.

$>$ Adequate performance. The closed-loop system tracks reference changes and suppresses disturbances as rapidly as possible. The larger the loop bandwidth, the faster the controller responds to changes in the reference or disturbances in the loop.

$>$ Adequate robustness. The loop design has enough gain margin and phase margin to allow for modeling errors or variations in system dynamics.

Figure 18 is the basic operational PID block diagram but it can be optimized using an extra internal PID loop in the block diagram in order to control the armature current in case of a failure as [26] suggests. The idea behind this internal loop is the case at which a very large load, bigger than the nominal load of the DC motor, is connected through the motor's axle. In that case, the motor will decrease its speed and the basic PID controller will increase the armature current, in order to drive the DC motor in a specific speed and torque output. The result is the overloading of the DC motor and its damage. Figure 19 illustrates the new PI block diagram using an internal armature PID controller loop.

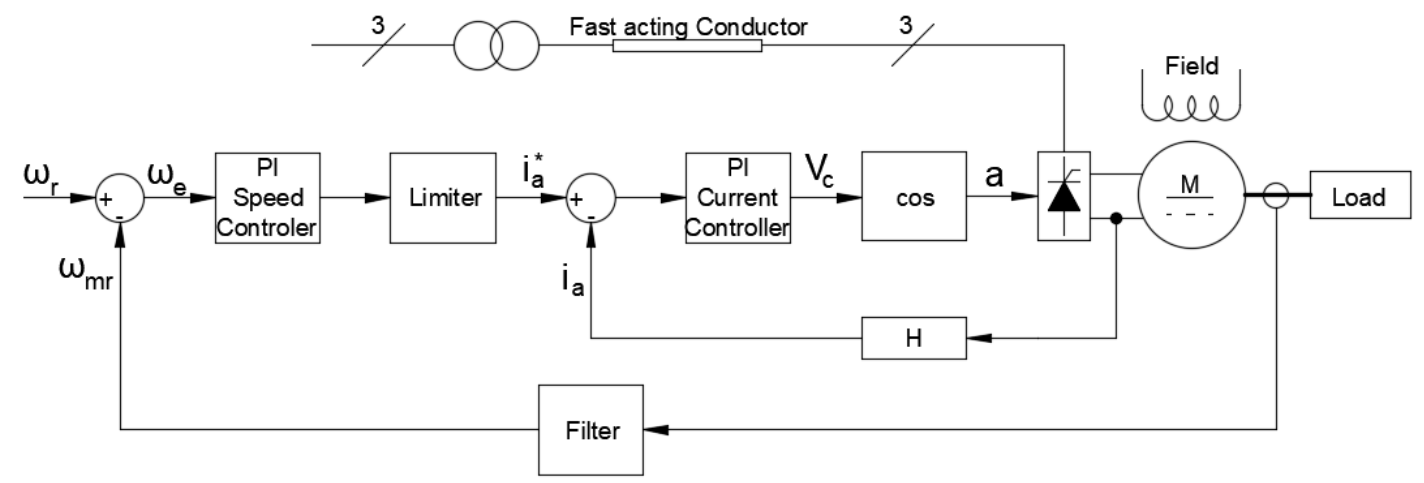

Figure 19. Speed controller two-quadrant dc motor drive [26]. 
There are a lot of applications using PID controller, in order to control DC or AC motors. Some of these applications use extra techniques and different technical approaches to drive a motor system [26,29,30]. In [26], as already mentioned, the usage of an extra internal PID controller is implemented in order to control armature current against overloading. In [29] another PI controller is implemented for a golf terrain. In this implementation, the reference input is given through the user. There is also a battery system and a buck converter used to ensure a type of autonomy for this system. The DC motor can be a Permanent Magnet DC motor (PMDC) and the implementation of PID controller is as simple as in a usual DC motor. Such an application is described in [30] where an extra hardware implementation technique uses a Field Programmable Gate Array (FPGA) in order to implement the PI controller. The usage of FPGA is a solution that avoids the high initial cost $[31,32]$ and the FPGA programmability permits design upgrades, with no hardware replacement necessary, which is impossible with classic Application-Specific Integrated Circuits (ASICs).

The next step of a controller system is the production of pulses to drive the power electronic topology, which is selected for the specific driving system. The most usual and dominant pulse production technique, for controlling the analog circuits using digital signals, is the Pulse Width Modulation (PWM) technique [33-35]. In [30], the PWM technique is implemented inside the same FPGA chip with the PI controller. This means an extra saving cost and a simpler hardware implementation.

\subsection{Intelligent Controllers}

Intelligent controllers are a particular category of controllers which use some special techniques in order to drive DC or AC motors. The idea behind an intelligent controller is the pre-schedule control procedure using a mathematical model of the system or a rule-based control procedure. For the proper design of a motor drive system, the motor's model, or in other words, its transfer function is needed. This transfer function is derived by applying basic electrical and motion equations, given the motor's parameters. It is not unusual either for model simplicity or because of inaccurate knowledge of the model itself, to model the motor with high amount of uncertainty in its transfer function. The intelligent control techniques attempts to address, overcome and finally solve. There are a lot of intelligent controllers such as Fuzzy Logic Controllers (FLC) and Artificial Neural Network Controllers (ANNC) and some of these intelligent controllers are illustrated below.

\subsubsection{Fuzzy Logic Controllers}

Fuzzy Logic Controllers (FLCs) use the so-called Fuzzy Logic Technique (FLT) in order to adequately control the drive system. The implementation of a FLC can be done as an individual part to produce the control signals for the PWM or in combination with a PID controller. Sen et al. [36] have included aspects of the fuzzy set theory in the control of DC motors back in 1996.

The basic constraints for DC motor drives are the non-linearity in dc motor, the variable and unpredictable inputs, the noise propagation along a series of unit processes, the unknown parameters and the changes in load dynamics [37]. The advantages of using FLT are the inherent approximation capability, the high degree of tolerance, the smooth operation, the reduction of the effect of non-linearity, the fast adaptation and the learning ability [37].

A Fuzzy Logic controller implements an if-then programming form for the various working conditions to control the motor speed. The Fuzzy logic control is a control algorithm based on a linguistic control strategy [38]. Crispy logic in Boolean theory is based on certain and precise situations in contrast to the Fuzzy logic. The variables in fuzzy logic have set of values which are expressed by linguistic expressions, such as SMALL, MEDIUM and LARGE [39]. These linguistic expressions are represented numerically by fuzzy sets. Every fuzzy set is characterized by a membership function, which varies between 0 and 1 in contrast to the Boolean sets, which can take values 0 or 1 [38]. A given element can be a member of a fuzzy set with a degree varying from 0 to 1 . The basic structure of a FLC is illustrated in Figure 20. The basic Fuzzy Controller parts are [35,36,40]: 
$>$ Fuzzification

$>$ Rule Base-Inference Engine

$>$ Defuzzification

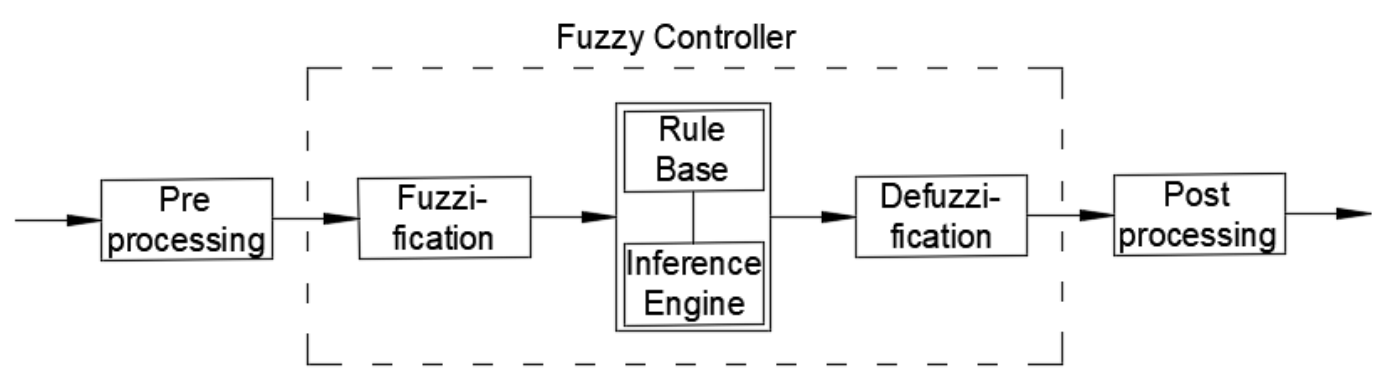

Figure 20. Structure of Fuzzy Logic controller.

During the fuzzification step, the crisp data, which come from some measuring equipment, are converted into degrees of membership by a lookup in one or several membership functions. The fuzzification block matches the input data with the conditions of the rules to determine. There is a degree of membership for each linguistic term that applies to the input variable [37].

The rule base is the collection of rules that the controller should meet. The rules are in "if-then" format and formally the "If" side is called the conditions and the "Then" side is called the conclusion. The computer is able to execute the rules and compute a control signal depending on the measured inputs error (e) and the change in error $\mathrm{d}(\mathrm{e})$ [37]. The number of rules in a fuzzy logic controller depends on the number of input and output variables and the number of membership functions.

During the fuzzification cycle, all the actions that have been activated are combined and converted into a single non-fuzzy output signal which is the control signal of the system. The output levels depend on the rules that the systems have in place, and the positions depend on the non-linearity's existing to the systems. Developing the control curve of the system, representing the I/O relation of the systems, and based on the information, the output degree of the membership function can be defined in order to minimize the effect of the non-linearity [37]. The most usual membership functions, for variable speed error and control output, are the triangular and the basic considerations of the control philosophy are [37]:

$>$ If both error and change of error is zero, then maintain the present control setting.

$>$ If the error is not zero but is approaching this value at a satisfactory rate, then maintain the present control setting.

$>$ If the error is growing then change the control signal output depending on the magnitude and sign of the error, to force the error towards zero.

The speed control of a separately excited DC motor can be implemented using the armature voltage variation, the field flux variation or the armature resistance variation [40]. The armature resistance speed control is not accepted because of the high-power losses.

In Reference [38], the armature voltage and field flux control methods are applied independently and finally are combined together on a single separately excited DC motor. These methods use also the fuzzy technique. The speed below the rated speed was achieved using the armature voltage speed control technique by varying the armature voltage in the constant torque region. The speed above the rated speed was achieved using the field current speed control technique by varying the field voltage in the constant power region. In the constant power region, field flux should be reduced to achieve speed above the rated speed [41]. According to the simulation results only the combined armature voltage and field control method is accurate and accepted. However, the combined armature voltage and field current control method is capable of an accurate description of the combined effects of the armature and field excitation to the motor. Also, the proposed combined technique offers the unique 
characteristic of controlling motor's speed below and above the rated speed. Additionally, it was observed that the armature voltage control method is closer to the proposed combined method with respect to the delay time, rise time and settling time, whereas the field control technique presents the highest overshoot in all cases and for different reference speed values.

\subsubsection{Artificial Neural Network Controllers (ANNC)}

Artificial Neural Network (ANN) is a form of artificial intelligence for emulating the human thinking process. It is different from the Fuzzy Logic Techniques which are rule-based techniques. There are a lot of different ANN controllers with the three most popular being:

$>$ Model predictive control

$>$ NARMA-L2 control

$>$ Model Reference control

ANN applications, on electrical drive systems, have got as basic idea to identify the mathematical model of the system's motor and using this model finally to control motor's speed [42]. In some cases, the adaptive control technique is applied in which the inverting forward ANN is used with some input parameters [43]. ANN techniques can be used in combination with PID control techniques, as proposed in [26], where two control strategies are proposed.

Neural networks permit the development of quantitative expressions without compromising the known complexity of the problem. They resemble the human brain in the following two ways [44]:

$>$ A neural network acquires knowledge through learning.

$>$ A neural network's knowledge is stored within inter-neuron connection strengths known as synaptic weights.

The reasons for using the ANN controllers broadly are the following [45]:

$>$ All the ANN signals are transmitted in one direction, the same as in automatically control system.

$>$ The ability of ANNs to learn the sample.

$>$ The ability to create the parallel signals in analog as well as in the discrete system.

$>$ The adaptive ability.

The structure of a neural network is composed of a large number of interconnected processing elements, named neurons, which work in unison to solve specific problems. ANNs learn by example like people do. Each ANN structure can be applied to solve a specific problem and is configured through a learning process $[44,45]$. Neural networks have got the ability of being applied both on linear and non-linear systems, and they can extract system's relationships directly from the data being modeled.

Generally, a neural control scheme consists of two parts. The first part is the neural estimator which is used to estimate the motor speed. The second part is the neural controller which is used to generate a control signal for a converter. These two parts must be trained, in order to work as better as they can. This is the reason that these two parts are passing through a training procedure. In [45], this training procedure is applied using the Levenberg-Marquardt back propagation algorithm. To train ANNs, the input and output datasets have to be determined first, and then design the ANN's net by optimizing the number of hidden layers, the number of neurals of each layer as well as the input and output number and the transfer function.

A neural network consists of junctions which are connected with LINKS, also called processing units. For each junction, a number is attached called the weight of junction. The weights are the tools for the long-distance information storing in the neutral network. The learning process occurs with the appropriate modification of weights. These weights are modified so that the network input/output behavior is in consonance with the environment which provides the data. A single input neuron consists of a scalar input ' $\mathrm{p}$ ' multiplied by the scalar weight ' $\mathrm{w}$ ' to calculate the product ' $\mathrm{w} \times \mathrm{p}$ ' which 
is fed to the summer along with bias ' $b$ ' multiplied by ' 1 ' [44]. Figure 20 illustrates the basic neural network diagram.

In the basic ANN diagram showed in Figure 21, the net input is ' $w \times p+b^{\prime}$ and the output is ' $a=f(w \times p+b)^{\prime}$. The ' $f$ ' is the transfer function while the ' $w^{\prime}$ and ' $b$ ' are adjusted through learning rule [44]. In [44] simulation and comparison between PID, PI and ANN controllers are presented. According to the authors, ANNC have better performance by reducing the steady state error, the maximum overshoot the rise time and the settling time. Also, the ANNC have more sensitive responses against load disturbances in comparison to the classical PI and PID controllers. The higher rise time of the system, using ANN controller, compared to the rise times of the systems using the other controllers, is considered a disadvantage.

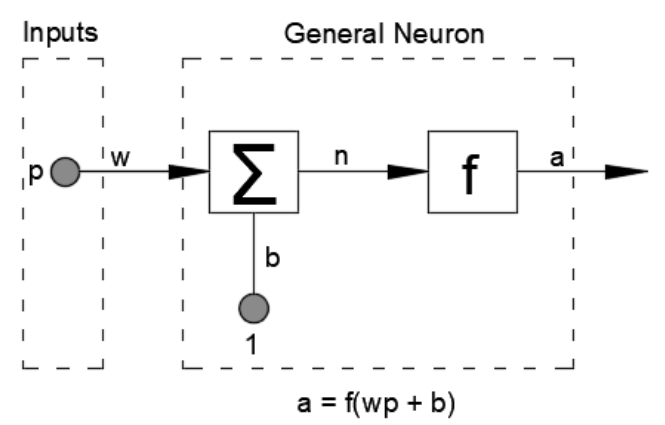

Figure 21. Basic Neural Network diagram [44].

Figure 22 illustrates the basic structure of an ANN model. Such a model is consisted of at minimum three layers. The first layer is the input layer. At this layer, all the measured parameters of a motor control system are fed into the ANN structure. The inputs pass through the hidden layers and the output layer is finally produced in order to send control signal to the power electronics. In this specific structure (Figure 22), a three-layer scheme is used. The inputs are the estimated speed $\omega_{\mathrm{p}}(\mathrm{k})$, the terminal voltage $V_{t}(k)$, the armature current $I_{a}(t)$ and the reference speed $\omega_{r}(t)$ as they are selected by the scheme designer in [45]. Figure 23 illustrates the ANN- training structure used by the authors of [45] in order to calculate the estimated speed $\omega_{\mathrm{p}}(\mathrm{k})$. For Figures 22 and $23 \mathrm{f} 1$ and $\mathrm{f} 2$ are the input and hidden layers' tansig-sigmoid activation functions, $\mathrm{V}_{\mathrm{t}}$ and $\mathrm{I}_{\mathrm{a}}$ are the measured terminal voltage and armature current and Alpha output is the control signal for the controller.

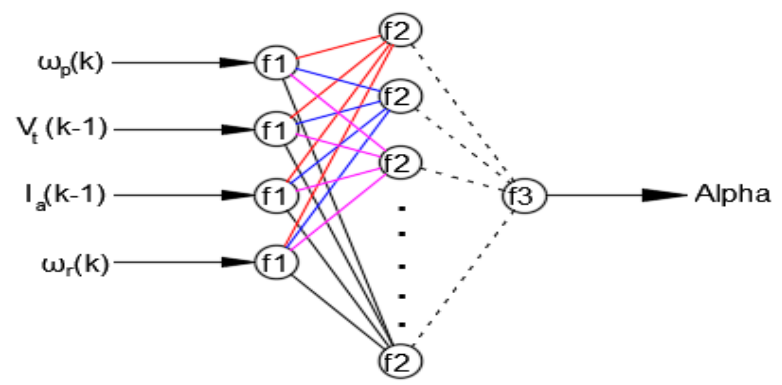

Figure 22. Basic ANN structure consisted of 3 layers [45].

Moreover, Table 3 presents the main characteristics for the control techniques applied in DC motor drive systems, which are described in this paper, and which namely are the classic PID(Proportional-Integral-Derivative) controllers and the intelligent controllers. About the intelligent controllers, these papers presented the most known categories, which are the fuzzy logic controllers and the controllers, based on artificial neural networks. 


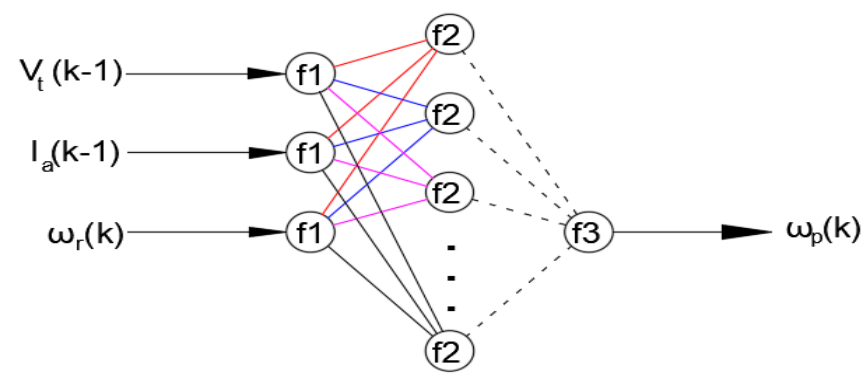

Figure 23. Basic ANN-training structure consisted of 3 layers [45].

Table 3. Control techniques for brushed DC motors drives.

\begin{tabular}{ll}
\hline Control objectives: & High performance motor drive system must have: \\
- Closed-loop stability & - Fast speed transient response \\
- Adequate performance & - Fast load transient response \\
- Adequate robustness & - High efficiency \\
& - Effective control \\
& - High reliability \\
\hline
\end{tabular}

Classic PID Controllers

- Modeling of individual parts of the system

- $\quad$ Requirement for a relatively accurate model

- $\quad$ Response and stability control applying Nyquist criterion and/or Bode diagrams

- Well known procedure
- $\quad$ PID calculation and optimization using:

- Ziegler-Nichols method

- Cohen-Coon method

- $\quad$ Manual tuning method

- $\quad$ Software tools (MATLAB tools)

Intelligent Controllers

\begin{tabular}{|c|c|}
\hline Fuzzy Logic & Artificial Neural Networks (ANN) \\
\hline $\begin{array}{l}\text { - Implements an if-then programming form for } \\
\text { the various working conditions to control the } \\
\text { motor speed } \\
\text { - } \quad \text { High precision modeling is not required } \\
\text { - Systematic way to take under consideration } \\
\text { model's unintentional or/and } \\
\text { intentional uncertainty } \\
\text { - Inherent approximation capability } \\
\text { - High degree of tolerance } \\
\text { - Smooth operation } \\
\text { - Learning ability }\end{array}$ & 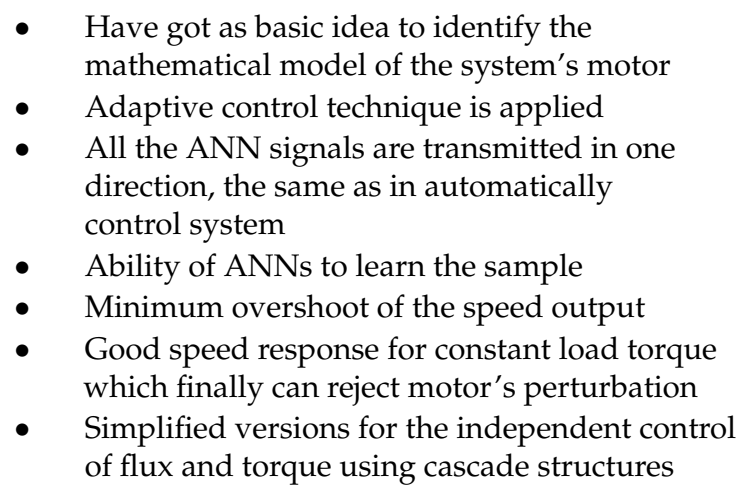 \\
\hline
\end{tabular}

\section{Semi-Quantitative Comparative Assessment}

In this section a semi-quantitative comparative assessment for brushed DC motor drives is attempted. As it has been presented in the previous sections, Tables 1 and 2 presents the basic characteristics of the controlled rectifier-fed and chopper-fed motor drives suitable for brushed DC motor drives.

Table 4 is an effort to summarize, in a compact shape, the advantages and disadvantages of different converter topologies combined with control methods, suitable for driving brushed DC motors. This assessment takes into consideration some of the most important or most commonly referring characteristics like quadrants of operation, power level, operation frequency, energy efficiency, output ripple current, transient response and level of complexity. 
Table 4. Comparative assessment of converters for brushed DC motor drives.

\begin{tabular}{|c|c|c|c|c|c|c|c|}
\hline Parameters & $\begin{array}{l}\text { Quadrants of } \\
\text { Operation }\end{array}$ & Power Level & Efficiency & Frequency & $\begin{array}{l}\text { Ripple } \\
\text { Current }\end{array}$ & $\begin{array}{l}\text { Transient } \\
\text { Response }\end{array}$ & Complexity \\
\hline $1 \Phi$ half wave & 1 & low & medium to high & low & high & slow & low \\
\hline $1 \Phi$ asymmetrical converter & 1 & medium & medium to high & low & high & slow & low \\
\hline $1 \Phi$ fully-controlled converter & 2 & medium & medium to high & low & high & slow & low \\
\hline $1 \Phi$ fully-controlled dual converter & 4 & medium & medium to high & low & high & slow & low \\
\hline $3 \Phi$ half-controlled converter & 1 & Medium to high & medium to high & low & high & slow & low to medium \\
\hline $3 \Phi$ fully-controlled converter & 2 & high to very high & medium to high & low & high & slow & low to medium \\
\hline $3 \Phi$ fully-controlled dual converter & 4 & high to very high & medium to high & low & high & slow & low to medium \\
\hline 1-switch chopper & 1 & low to medium & medium & medium & low & fast & low to medium \\
\hline 2Q chopper & 2 & low to medium & medium & medium & low & fast & low to medium \\
\hline H-Bridge chopper & 4 & medium & medium & medium & low & fast & low to medium \\
\hline 2Q-ZVMR converter & 2 & low to medium & high & high & very low & very fast & medium to high \\
\hline 2Q ZVT converter & 2 & low to medium & high & high & very low & very fast & medium to high \\
\hline 2Q ZCT converter & 2 & low to medium & high & high & very low & very fast & medium to high \\
\hline 4Q ZVT converter & 4 & medium & high & high & very low & very fast & high \\
\hline 4Q ZCT converter & 4 & medium & high & high & very low & very fast & high \\
\hline
\end{tabular}


As the quantitative approach on such effort is not possible as the values of the above mentioned characteristics depend on the size and type of the motor, the application and other factors, this approach is based on a qualitative and semi-quantitative representation of these important and critical operational parameters, aiming to deliver a decision support view in the scientific and engineering community.

\section{Conclusions}

This paper offers an extensive review of the basic topologies, and control methods and techniques applied in conventional and modern brushed DC motor drives, for industrial and automobile applications. The field of applications of each power circuit topology, include the advantages, disadvantages, as well the control techniques presented for each case.

DC motor drives are still used and have evolved due to the exceptional characteristics of DC motors. Different and varied application requirements make the use of drive systems mandatory, with less or more complex control systems. The modern industry uses complex power systems to meet the growing needs of society for newly developed products, and faster production rates, respectively.

The maturity of advanced control techniques such as Fuzzy Logic (FL) and Artificial Neural Network (ANN) have made possible to embed them into modern, high standard controllers specialized for high efficiency motor drives.

Additionally, the new legislation on the eco-design of the systems and the high efficiency requirements, have led to the development of new strategies in the field of electric motor control.

Author Contributions: Conceptualization, D.A.B., G.C.I. and C.S.P.; methodology, G.C.I. and C.S.P.; validation, G.V. and S.D.K.; formal analysis, D.A.B., G.C.I. and C.S.P.; investigation, D.A.B.; resources, D.A.B., G.C.I. and G.A.V.; data curation, D.A.B., G.C.I. and S.D.K.; writing-original draft preparation, D.A.B. and G.C.I.; writing-review and editing, D.A.B., G.C.I. and C.S.P.; visualization, D.A.B., G.C.I. and C.S.P.; supervision, G.C.I.; project administration, G.C.I. and C.S.P. All authors have read and agreed to the published version of the manuscript.

Funding: This research received no external funding.

Conflicts of Interest: The authors declare no conflict of interest.

\section{References}

1. Chapman, S.J. Electric Machinery Fundamentals; WCB/McGraw-Hill: New York, NY, USA, 1998.

2. Mohan, N.; Undeland, T.M. Power Electronics, Converters, Applications and Design; John Wiley \& Sons: New York, NY, USA, 1995.

3. Manias, S.N. Power Electronics; Simeon Publications: Athens, Greece, 2012. (In Greek)

4. Malatestas, P. Motor Drives; Tziolas Publications: Athens, Greece, 2013. (In Greek)

5. Williams, B.W. Power Electronics: Devices, Drivers, Applications, and Passive Components; University of Strathclyde: Glasgow, UK, 2006.

6. Nedeljkovic, M.; Stojiljkovic, Z. Fast current control for thyristor rectifiers. IEE Proc. Electr. Power Appl. 2003, 150, 636-638. [CrossRef]

7. Consoli, A.; Cacciato, M.; Testa, A.; Gennaro, F. Single chip integration for motor drive converters with power factor Capability. IEEE Trans. Power Electron. 2004, 19, 1372-1379. [CrossRef]

8. Daigavane, M.; Suryawanshi, H.; Khan, J.A. Novel Three Phase Series-Parallel Resonant Converter Fed DC-Drive System. J. Power Electron. 2007, 7, 222-232.

9. Gupta, R.; Lamba, R.; Padhee, S. Thyristor based speed control techniques of DC motor: A comparative analysis. Int. J. Sci. Res. Publ. 2012, 2, 1-6.

10. Chau, K.T.; Lee, Y.S.; Ioinovici, A. Computer-aided modeling of quasi-resonant converters in the presence of parasitic losses by using MISSCO concept. IEEE Trans. Ind. Electron. 1991, 38, 454-461. [CrossRef]

11. Chan, C.C.; Chau, K.T. A new zero-voltage-switching dc/dc boost converter. IEEE Trans. Aerosp. Electron. Syst. 1993, 29, 125-134. [CrossRef]

12. Chau, K.T. New Constant-frequency multi-resonant boost convertor. IEE Electron. Lett. 1994, 30, 101-102. [CrossRef] 
13. Chong, C.C.; Chan, C.Y.; Foo, C.F. A quasi-resonant converter-fed dc drive system. In Proceedings of the European Power Electronics Conference, Brighton, UK, 13-16 September 1993; pp. 372-377.

14. Hua, G.; Lee, F.C. Soft-switching Techniques in PWM Converters. IEEE Trans. Ind. Electron. 1995, 42, 595-603. [CrossRef]

15. Luo, F.L.; Jin, L. Two-quadrant DC/DC Soft-switching Converter. Proc. IEEE Power Electron. Spec. Conf. 2000, 1, 173-178.

16. Uma, G.; Chellamuthu, C. Modeling and Design of Fuzzy Speed Controller for Constant Frequency Zero Current Switched Converter Fed DC Servo Motor for Battery Operated Vehicles. Proc. Int. Conf. Power Syst. Technol. 2000, 1, 211-215.

17. Ching, T.W. Soft-switching converters for electric vehicle propulsion. J. Asian Electr. Veh. 2007, 5, 1019-1026. [CrossRef]

18. Chau, K.T.; Ching, T.W.; Chan, C.C. Constant frequency multi-resonant converter-fed dc motor drives. In Proceedings of the IEEE Industrial Electronics, Control, and Instrumentation Conference, Taipei, Taiwan, 9 August 1996; pp. 78-83.

19. Chau, K.T.; Ching, T.W. A new two-quadrant zero voltage transition converter for dc motor drives. Int. J. Electron. 1999, 86, 217-231. [CrossRef]

20. Ching, T.W.; Chau, K.T. A new two-quadrant zero current transition converter for dc motor drives. Int. J. Electron. 2001, 88, 719-735. [CrossRef]

21. Ching, T.W. Four-quadrant zero-voltage-transition converter-fed dc motor drives for electric propulsion. J. Asian Electr. Veh. 2005, 3, 651-656. [CrossRef]

22. Ching, T.W. Four-quadrant zero-current-transition converter-fed dc motor drives for Electric Propulsion. J. Asian Electr. Veh. 2006, 4, 911-918. [CrossRef]

23. Grassi, E.; Tsakalis, K. PID Controller Tuning by Frequency Loop-Shaping: Application to Diffusion Furnace Temperature Control. Proc. IEEE Trans. Control Syst. Technol. 2000, 8, 842-847. [CrossRef]

24. Loucif, F. DC Motor Speed Control using PID Controller. In Proceedings of the International Conference on Control, Automation and Systems (ICCAS), KINTEX, Gyeonggi-Do, Korea, 2-5 June 2005.

25. Ioannidis, G.C.; Kaminaris, S.D.; Psomopoulos, C.S.; Tsiolis, S.; Pachos, P.; Villiotis, I.; Malatestas, P. DC Motor Drive Applying Conventional and Fuzzy Based PI Control Techniques. JARR 2015, XV, 1-10.

26. Singh, B.; Prakash, S.; Pandey, A.S.; Sinha, S.K. Intelligent PI Controller for Speed Control of D.C. Motor. Int. J. Electron. Eng. Res. 2010, 2, 87-100.

27. Mishra, G.K.; Pandey, A.K.; Maurya, A. Combined Armature and Field Speed Control of DC Motor for Efficiency Enhancement. SSRG Int. J. Electr. Electron. Eng. (SSRG-IJEEE) 2014, 1, 34-39.

28. Zaccarian, L. DC Motors: Dynamic Model and Control Techniques; Lecture Notes. Roma, Italy, 2012. Available online: http://control.disp.uniroma2.it/zack/LabRob/DCmotors.pdf (accessed on 15 May 2020).

29. Haishui, Z.; Dahu, W.; Tong, Z.; Keming, H. Design on a dc motor speed control. In Proceedings of the International Conference on Intelligent Computation Technology and Automation, Changsha, China, 11-12 May 2010. [CrossRef]

30. Aruna, K.; Pravin, M.R.; Ramachandran, J.; Sudheer, S.; Sathiyasekar, K. Design and Implementation of PI Controller for the Speed Control of DC Motor in Cooling System. Int. J. Eng. Trends Technol. (IJETT) 2014. [CrossRef]

31. Castano, L.F.; Osorio, G.A. Design of a FPGA based position PI servo controller for a DC Motor with dry friction. In Proceedings of the 2011 VII Southern Conference on Programmable Logic (SPL), Cordoba, Argentina, 13-15 April 2011; ISBN 978-1-4244-8848.

32. Zhang, D.; Li, H.; Collins, E.G. Digital Anti-Windup PI Controllers for Variable-Speed Motor Drives Using FPGA and Stochastic Theory. Proc. IEEE Trans. Power Electron. 2006, 21, 1496-1501. [CrossRef]

33. Zenginobuz, G.; Bilgin, H.F.; Kose, K.N.; Ermis, M. A Unity Power Factor Buck-Type PWM Rectifier for Medium/High- Power DC Motor Drive Applications. Proc. IEEE Trans. Ind. Appl. 2002, 38, 1412-1425.

34. Chen, J.; Tang, P.C. A Sliding Mode Current Control Scheme for PWM Brushless DC Motor Drives. Proc. IEEE Trans. Power Electron. 1999, 14, 541-551. [CrossRef]

35. Lim, C.S.; Levi, E.; Rahim, N.A.; Hew, W.P. A Comparative Study of Synchronous Current Control Schemes Based on FCS-MPC and PIPWM for a Two-Motor Three-Phase Drive. IEEE Trans. Ind. Electron. 2014, 61, 3867-3878. [CrossRef] 
36. Sen, P.C.; Namuduri, C.S.; Nandam, P.K. Evolution of control techniques for industrial drives. In Proceedings of the International Conference on Power Electronics, Drives and Energy Systems for Industrial Growth, New Delhi, India, 8-11 January 1996. [CrossRef]

37. Rai, J.N.; Singhal, M.; Nandwani, M. Speed Control of Dc Motor Using Fuzzy Logic Technique. IOSR J. Electr. Electron. Eng. (IOSR-JEEE) 2012, 3, 41-48. [CrossRef]

38. Sadiq, A.A.; Bakare, G.A.; Anene, E.C.; Mamman, H.B. A Fuzzy-Based Speed Control of DC Motor Using Combined Armature Voltage and Field Current. In Proceedings of the 3rd IFAC International Conference on Intelligent Control and Automation Science 2013, Chengdu, China, 2-4 September 2013.

39. Zadeh, L.A. Fuzzy Sets, Fuzzy Logic, Fuzzy Systems; World Scientific Press: Singapore, 1996; ISBN 9810224214.

40. Mendel, J. Fuzzy logic systems for Engineering applications. Proc. IEEE 1995, 83, 345-377. [CrossRef]

41. Mustapha, A. Speed Control of Dc Motor using Combined Armature and Field Control. Unpublished Ph.D. Thesis, Brno University of Technology, Brno, Czech Republic, 2005.

42. Dzung, P.Q.; Phuong, L.M. ANN- Control system de motor. IEEE Trans. Neural Netw. 2002, 82-90. Available online: http://www.nsl.hcmus.edu.vn/greenstone/collect/hnkhbk/import/Dien_tu/3_SectionA/10_ Phan\%20Quoc\%20Dzung,\%20Le\%20Minh\%20Phuong_ANN\%20-\%20CONTROL\%20SYSTEM\%20DC\% 20MOTOR.pdf (accessed on 18 May 2020).

43. Weerasoory, S.; AI-Sharkawi, M.A. Identification and control of d.c. motor using back propagation neural networks. IEEE Trans. Energy Convers. 1991, 6, 663-669. [CrossRef]

44. Kumar, S.B.; Ali, M.H.; Sinha, A. Design and Simulation of Speed Control of DC Motor by Artificial Neural Network Technique. Int. J. Sci. Res. Publ. 2014, 4, 1-4.

45. Madhusudhana Rao, G.; Sanker Ram, B.V. A Neural Network Based Speed Control for DC Motor. Int. J. Recent Trends Eng. 2009, 2, 121-124.

(C) 2020 by the authors. Licensee MDPI, Basel, Switzerland. This article is an open access article distributed under the terms and conditions of the Creative Commons Attribution (CC BY) license (http://creativecommons.org/licenses/by/4.0/). 